\title{
Primeira ocorrência de zirconolita na Província Alcalina do Sul do da Bahia: intrusão sienítica do Complexo Alcalino Floresta Azul, Bahia, NE Brasil
}

First occurrence of zirconolite in the South Bahia Alkaline Province: syenite intrusion of Floresta Azul Alkali Complex, Bahia, NE Brazil

\author{
J. J. A. Santos ${ }^{1 *}$; A. C. S. Pimenta ${ }^{1}$; M. L. S. Rosa ${ }^{1}$; H. Conceição ${ }^{1}$ \\ ${ }^{1}$ Laboratório de Petrologia Aplicada à Pesquisa Mineral (LAPA-UFS ), Programa de Pós-Graduação em \\ Geociêncas e Análise de Bacias (PGAB-UFS), Complexo Laboratorial da Universidade Federal de Sergipe, \\ Prédio das Geociências, 49100-000, São Cristóvão-SE, Brasil
}

*jailson_jras@hotmail.com

(Recebido em 26 de maio de 2015; aceito em 10 de agosto de 2015)

\begin{abstract}
Cristais de zirconolita $\left(\mathrm{CaZrTi}_{2} \mathrm{O}_{7}\right)$ anédricos e subédricos, e com tamanhos inferiores a $20 \mu \mathrm{m}$ foram identificados pela primeira vez na Província Alcalina do Sul do Estado da Bahia em sienitos do Complexo Alcalino Floresta Azul. Nesse estudo utilizou-se um microscópio eletrônico de varredura com detectores de elétrons secundários, elétrons retroespalhados e espectrômetro de energia dispersiva. A zirconolita é magmática e ocorre inclusa em oligoclásio antipertítico e microclina pertítica, estando usualmente em associação com baddeleíta, thorianita, zircão, monazita, esfalerita, pirita e ilmenita. Os dados químicos obtidos para os cristais de zirconolita estudados revelaram que eles são homogêneos e suas composições semelhantes àquelas descritas na literatura para zirconolitas de foid-sienitos e carbonatitos.
\end{abstract}

Palavras-chave: Mineralogia, Zirconolita, Estado da Bahia

Zirconolite crystals $\left(\mathrm{CaZrTi}_{2} \mathrm{O}_{7}\right)$ anhedral, subhedral and sizes less than $20 \mu \mathrm{m}$ were first identified in the South Bahia Alkaline Province from syenites the Floresta Azul Alkaline Complex. In this study we used a scanning electron microscope with secondary electron detectors, backscattered electrons and energy dispersive spectrometer. The zirconolite is included in antiperthite oligoclase and perthite microcline, usually being in association with baddeleyite, zircon, monazite, ilmenite and pyrite. The chemical data for zirconolite crystals studied revealed that they are homogeneous and their compositions are similar to those described in the literature for the zirconolita from foid syenites and carbonatites.

Keywords: Mineralogy, Zirconolite, Bahia State

\section{INTRODUÇÃO}

A zirconolita $\left(\mathrm{CaZrTi}_{2} \mathrm{O}_{7}\right)$ é um mineral acessório raro, que tem sido identificado em vários tipos de rochas: meteoritos [1, 2], anortositos lunares [3], foid-sienitos [4], xenólitos mantélicos [5], suítes ultramáficas [6], kimberlitos [7], carbonatitos [8], safirina-granulitos [9], skarns [10], pegmatitos [11], meta-carbonatos [12] e lateritas [13]. Todavia, a zirconolita é relativamente comum em rochas evoluídas de suítes alcalinas subsaturadas em $\mathrm{SiO}_{2}$ [10]. A depender do tipo de rocha onde ocorra, a zirconolita apresenta composição química que permite inferir a natureza do magma onde cristalizou $[14,15]$.

Em 2014, com o auxílio da microscopia eletrônica de varredura iniciaram-se estudos da mineralogia acessória em rochas da Província Alcalina do Sul do Estado da Bahia (PASEBA). Essas análises tornaram possível a identificação de minerais até então desconhecidos nessa província, e.g. ancilita [ $\left.\mathrm{Sr}(\mathrm{Ce}, \mathrm{La})\left(\mathrm{CO}_{3}\right)_{2}(\mathrm{OH}) \cdot \mathrm{H}_{2} \mathrm{O}\right]$ [16], pirocloro [(Ca,Na) $\left.\mathrm{Nb}_{2} \mathrm{O}_{6}(\mathrm{OH}, \mathrm{F})\right]$ [17]. Nesse trabalho descreve-se e discute-se a presença de zirconolita na paragênese acessória de sienitos do Complexo Alcalino Floresta Azul (CAFA). 


\section{GEOLOGIA DA ÁREA DE ESTUDO}

A PASEBA (Figura 1A) corresponde a uma província neoproterozoica [18] cujos corpos mostram-se alinhados NE-SW e intrusivos em metamorfitos arqueanos-paleoproterozoicos (Figura 1B). Essa província é constituída essencialmente por nefelina sienitos, sodalita sienitos, nefelina monzonitos, existindo de forma subordinada álcali-basaltos, quartzo sienitos, granitos, riolitos, traquitos e fonólitos [19, 20, 21, 22, 23].

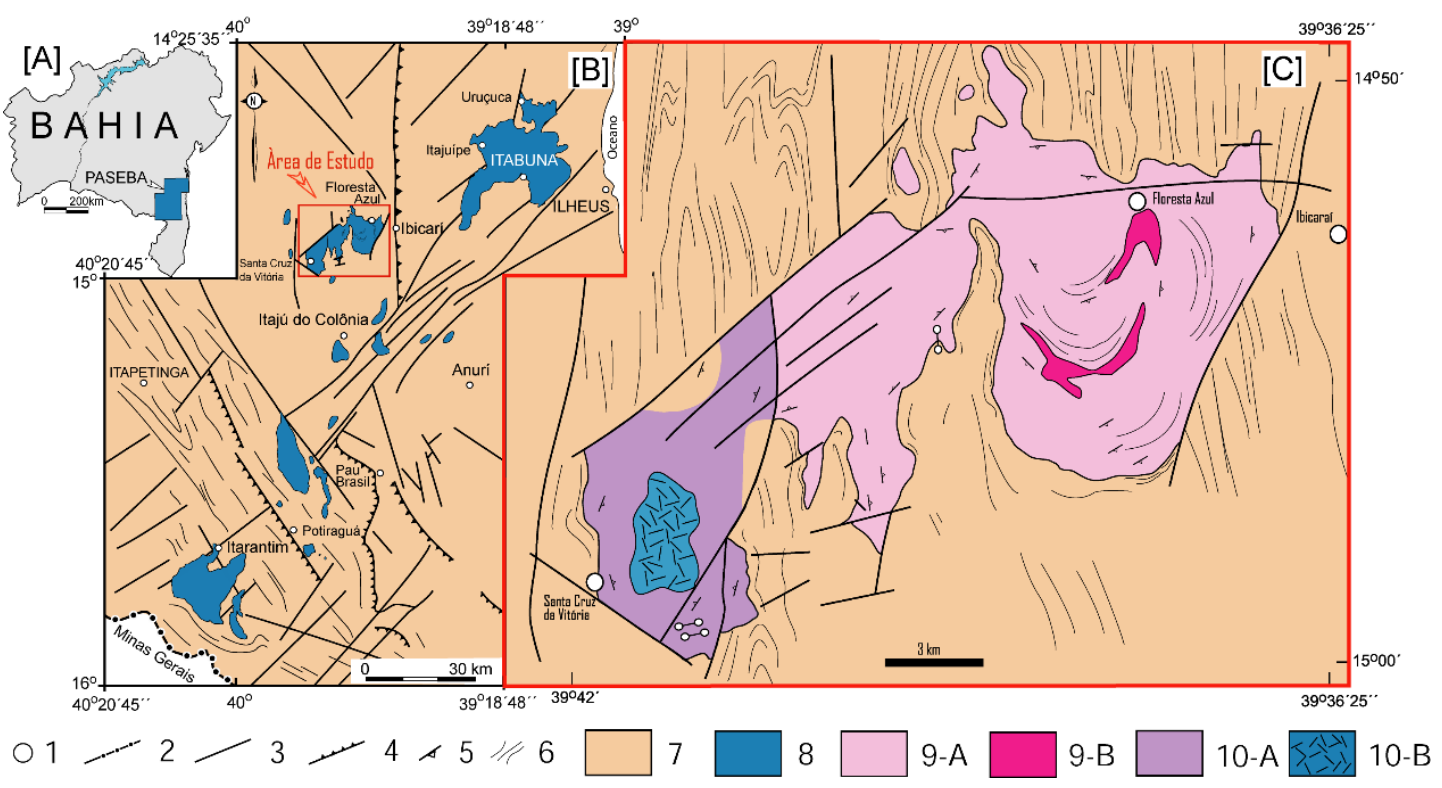

Figura 1: Contorno do Estado da Bahia apresentando a localização da Província Alcalina do Sul do Estado da Bahia [18] (A). Distribuição dos corpos desta província (B) com a localização do Complexo Alcalino Floresta Azul (C). Esquema geológico do CAFA apresentando as intrusões sienítica e granítica. Cidades (1), limite interestadual (2), falhas (3), falhas de cavalgamento (4), foliação magmática (5), lineamento fotogeológico (6), metamorfitos do embasamento (7), corpos alcalinos (8), Intrusão Granítica (9, $A=$ granitos alcalinos com enclaves dioríticos; $B=$ granitos alcalinos com mais de $50 \%$ de enclaves dioríticos), Intrusão Sienítica (10, A= sienitos e $B=$ foid-sienitos).

O Complexo Alcalino Floresta Azul, com área de $200 \mathrm{~km}^{2}$, está situado entre as cidades de Ibicaraí e Santa Cruz da Vitória, distando cerca de 500 km de Salvador, no Estado da Bahia. Esse complexo corresponde a um dos batólitos da PASEBA (Figura 1C), sendo formado por duas intrusões distintas que fazem contato por falha [24]. A intrusão granítica situa-se a leste e a intrusão sienítica a oeste (Figura 1C).

A idade de $688 \pm 10$ Ma foi obtida [24] para a cristalização das rochas da Intrusão Sienítica (ISn) do CAFA. Na zona periférica da ISn os sienitos contêm quartzo, sendo esse mineral ausente em outras regiões do corpo, e o volume de feldspatóides cresce da periferia em direção ao centro da intrusão, onde aparecem os nefelina sienitos [23, 24]. Na região central tem-se os termos mais evoluídos representados por sodalita sienitos e sodalititos de cor azul que são explorados como rochas ornamentais. As presenças de sodalititos no centro da intrusão e de sienitos com quartzo na borda foram interpretadas [23] como indicativo de que nessa intrusão estiveram ativos os processos de cristalização fracionada e contaminação pelas encaixantes metamórficas saturadas em sílica.

Santos (2013) [23] identifica na ISn a presença de vários tipos de sienitos: annita foid-sienito; foid-sienito; foid-sienito porfirítico; e álcali-sienito (com ou sem quartzo). Os sienitos apresentam textura fanerítica grossa a pegmatítica, com cristais hipidiomórficos e sem orientação. O principal mineral máfico encontrado nesses sienitos é a annita, sendo que diopsídio, biotita, aegirina-augita e hornblenda ocorrem de forma subordinada. A nefelina ocupa os interstícios formados pelos cristais subédricos de feldspato alcalino pertítico ou antipertítico. Os cristais de sodalita, por sua vez, são formados a partir da nefelina, e ambos mostram-se total 
ou parcialmente transformados para cancrinita ou carbonato. Fraturas e clivagens em cristais de feldspato alcalino e biotita são normalmente preenchidos por carbonato.

\section{MATERIAL E MÉTODOS}

O estudo petrográfico de amostras da ISn do CAFA foi feito em lâminas delgado-pólidas, com dimensões de $27 \mathrm{~mm}$ por $46 \mathrm{~mm}$. Essas lâminas foram analisadas incialmente em microscópio petrográfico com luz transmitida e refletida de marca Opton (TNP-09NT), do Laboratório de Microanálise do Condomínio de Laboratórios Multiusuários das Geociências (CLGeo) da Universidade Federal de Sergipe.

$\mathrm{Na}$ amostra 2202, que corresponde a um álcali-sienito com diopsídio e biotita, identificou-se a presença de cristais diminutos $(<20 \mu \mathrm{m})$ de zirconolita, os quais ocorrem com formas variáveis e inclusos em cristais de feldspato alcalino pertítico ou antipertítico e oligoclásio antipertítico. Cristais com essas dimensões não são possíveis de serem identificados em estudo de petrografia clássica.

A localização e análise dos cristais de zirconolita foram feitas com o uso do microscópio eletrônico de varredura (MEV), marca Tescan ${ }^{\circledR}$ (Vega 3), do CLGeo, utilizando detectores para a captação de elétrons secundários (SE) e elétrons retroespalhados (BSE). A determinação da composição química foi feita utilizando-se espectrômetro de energia dispersiva (EDS) da marca Oxford Instrumentos ${ }^{\circledR}$ (X-Act). A precisão nos resultados dos elementos dosados varia entre $10 \%$ e $20 \%$. As condições analíticas foram uma aceleração potencial de $15 \mathrm{Kv}$ e corrente variando de $15 \mathrm{nA}$ a $20 \mathrm{nA}$, gerando um feixe de elétrons com diâmetro compreendido entre $300 \mathrm{~nm}$ a $830 \mathrm{~nm}$.

\section{RESULTADOS E DISCUSSÃO}

Os cristais de zirconolita, observados em sienitos do CAFA, são subédricos e anédricos, apresentando diâmetros compreendidos entre 2 e $20 \mu \mathrm{m}$. Eles ocorrem como inclusões em cristais de feldspato alcalino pertítico ou antipertítico e oligoclásio antipertítico (Figura 2). Normalmente localizam-se nos contatos entre as fases potássica e sódica nesses cristais. E, mostram-se associados a cristais de zircão, baddeleíta, pirita, ilmenita, monazita, thorianita e esfalerita.

Os dados químicos representativos dos cristais estudados estão apresentados na tabela 1. A fórmula cristaloquímica geral para os minerais do Grupo da Zirconolita pode ser representada como $\mathrm{M}(1)_{2}{ }^{\mathrm{VIII}} \mathrm{M}(2)_{2}{ }^{\mathrm{VII}} \mathrm{M}(3)^{\mathrm{VI}} \mathrm{M}(4)^{\mathrm{IV}, \mathrm{V}} \mathrm{O}_{14}$, tendo como o membro puro do grupo $\mathrm{Ca}_{2}{ }^{\mathrm{VIII}} \mathrm{Zr}_{2}{ }^{\mathrm{VII}}$ $\mathrm{Ti}_{3}{ }^{\mathrm{VI}} \mathrm{Ti}^{\mathrm{V}} \mathrm{O}_{14}$ [25]. O íon $\mathrm{Ca}^{+2}$ tem coordenação 8 no sítio $\mathrm{M}(1)$ e pode ser substituído pelos Elementos Terras Raras $\left(\mathrm{ETR}^{+3}\right), \mathrm{Fe}^{+2}, \mathrm{Mg}^{+2}, \mathrm{Mn}^{+2}, \mathrm{Zn}^{+2}, \mathrm{Co}^{+2}, \mathrm{Na}^{+}$e $\mathrm{Y}^{+3}$. O íon $\mathrm{Zr}^{+4}$ tem coordenação 7 no sítio $\mathrm{M}(2)$ e pode ser substituído por $\mathrm{Hf}^{+4}, \mathrm{Ti}^{+3}$ e esporadicamente por $\mathrm{U}^{+4}$, $\mathrm{Th}^{+4}, \mathrm{~Pb}^{+2}, \mathrm{ETR}^{+3}, \mathrm{Y}^{+3}$. O íon $\mathrm{Ti}^{+4}$ posiciona-se nos sítios $\mathrm{M}(3)$ e $\mathrm{M}(4)$, apresenta-se em coordenações 6 e 5 respectivamente, e pode ser substituído por $\mathrm{Zr}^{+4}, \mathrm{Al}^{+3}, \mathrm{Fe}^{+3}, \mathrm{Mg}, \mathrm{Mn}, \mathrm{Cr}^{+3}$, $\mathrm{Si}^{+4}, \mathrm{~W}^{+5}, \mathrm{Nb}^{+5}, \mathrm{Ta}^{+5}[4,12,26,27,28]$.

A composição química dos cristais analisados (Tabela 1) apresenta variação de: 32,0-36,1\% $\mathrm{ZrO}_{2} ; \quad 23,6-29,3 \% \quad \mathrm{TiO}_{2} ; \quad 6,3-10,1 \% \quad \mathrm{CaO} ; \quad 4-8,1 \% \quad \mathrm{FeO} ; \quad 7,7-11,3 \% \quad \mathrm{Nb}_{2} \mathrm{O}_{5} ; \quad 0,5-10,9 \%$ $\mathrm{ThO}_{2}+\mathrm{UO}_{2} ; 4,4-7,9 \% \mathrm{ETR}_{2} \mathrm{O}_{3}$; e até $6,1 \% \mathrm{Y}_{2} \mathrm{O}_{3}$. A soma total de cátions na fórmula estrutural da maioria dos cristais de zirconolita, calculada com base em sete oxigênios, varia de 3,953 a 3,995 , indicando que os resultados obtidos são satisfatórios. As análises de número 23 até 28 , com altos conteúdos de $\mathrm{ThO}_{2}(6,25-8,5 \%)$ e $\mathrm{UO}_{2}(2-3 \%)$, apresentam os valores mais baixos do total de cátions $(3,827$ a 3,857$)$.

A literatura descreve o processo de cristalização da zirconolita como podendo ocorrer em condições magmática, metassomática [29] e metamórfica [10, 30, 31, 32]. A cristalização de zirconolita em magmas subsaturados em óxido de silício é usual e bem documentada em carbonatitos [8], foid-sienitos [4], kimberlitos [7], rochas ultrabásicas [6] e rochas ultrapotássicas [5]. 
Tabela 1. Análises representativas de cristais de zirconolita da Intrusão Sienítica do CAFA.

\begin{tabular}{|c|c|c|c|c|c|c|c|c|c|c|c|c|}
\hline & 2 & 6 & 7 & 9 & 10 & 11 & 18 & 23 & 24 & 27 & 28 & 29 \\
\hline $\mathrm{ZrO}_{2}$ & 34,1 & 34,6 & 33,7 & 34,3 & 35,0 & 35,1 & 34,6 & 32,5 & 33,0 & 33,1 & 32,0 & 36,1 \\
\hline $\mathrm{TiO}_{2}$ & 25,4 & 26,8 & 27,8 & 27,1 & 28,4 & 27,0 & 29,3 & 23,6 & 25,2 & 24,0 & 24,2 & 26,9 \\
\hline $\mathrm{CaO}$ & 7,8 & 8,7 & 8,6 & 8,0 & 8,9 & 8,5 & 9,3 & 7,5 & 10,1 & 6,3 & 7,3 & 8,5 \\
\hline $\mathrm{FeO}$ & 7,2 & 7,9 & 8,1 & 7,9 & 7,3 & 7,4 & 7,7 & 6,9 & 4,5 & 4,4 & 4,0 & 6,6 \\
\hline $\mathrm{Nb}_{2} \mathrm{O}_{5}$ & 10,4 & 9,3 & 10,1 & 9,5 & 7,7 & 10,2 & 9,2 & 9,5 & 10,5 & 11,3 & 10,0 & 8,9 \\
\hline $\mathrm{ThO}_{2}$ & 1,5 & 1,8 & 1,7 & 2,8 & 1,7 & 1,3 & 0,9 & 6,2 & 7,7 & 7,5 & 6,8 & 2,2 \\
\hline $\mathrm{UO}_{2}$ & 0,6 & & 0,5 & 0,5 & 0,7 & & 0,3 & 2,1 & 2,4 & 3,0 & 2,1 & 0,4 \\
\hline $\mathrm{Al}_{2} \mathrm{O}_{3}$ & 0,7 & 0,6 & & 0,9 & 0,6 & 0,6 & 0,7 & & & & 1,6 & 0,6 \\
\hline $\mathrm{SiO}_{2}$ & & 1,0 & 1,3 & 1,7 & 0,9 & 1,0 & 0,6 & & & & 3,3 & 0,8 \\
\hline $\mathrm{Y}_{2} \mathrm{O}_{3}$ & 2,9 & 2,6 & & 2,9 & 2,7 & 2,6 & & 3,9 & & 4,8 & 2,3 & 3,3 \\
\hline $\mathrm{Ce}_{2} \mathrm{O}_{3}$ & 3,2 & 3,2 & 4 & & 3,0 & 2,7 & 3,7 & 3,0 & 3,8 & 2,7 & 3,6 & 3,0 \\
\hline $\mathrm{Nd}_{2} \mathrm{O}_{3}$ & 3,3 & 3,4 & 3,8 & 4,4 & 2,9 & 3,3 & 2,8 & 3,0 & 2,5 & 2,8 & 2,4 & 2,6 \\
\hline $\mathrm{Dy}_{2} \mathrm{O}_{3}$ & 1,4 & & & & & & & & & & & \\
\hline $\mathrm{HfO}_{2}$ & & 0,1 & 0,3 & & 0,3 & 0,2 & 0,3 & & & & & \\
\hline $\mathrm{Ta}_{2} \mathrm{O}_{5}$ & 1,3 & & & & & & 0,7 & & & & & \\
\hline Total & 99,8 & 100,0 & 99,9 & 100,0 & 100,1 & 99,9 & 100,1 & 98,2 & 99,7 & 99,9 & 99,6 & 99,9 \\
\hline \multicolumn{13}{|c|}{ Fórmula Estrutural (7 oxigênios) } \\
\hline $\mathrm{Ca}$ & 0,537 & 0,585 & 0,578 & 0,532 & 0,597 & 0,567 & 0,616 & 0,536 & 0,713 & 0,450 & 0,497 & 0,573 \\
\hline $\mathrm{Y}$ & 0,099 & 0,087 & & 0,096 & 0,090 & 0,086 & & 0,139 & 0,000 & 0,170 & 0,078 & 0,110 \\
\hline $\mathrm{Ce}$ & 0,075 & 0,074 & 0,092 & & 0,069 & 0,062 & 0,084 & 0,073 & 0,092 & 0,066 & 0,084 & 0,069 \\
\hline $\mathrm{Nd}$ & 0,076 & 0,076 & 0,085 & 0,098 & 0,065 & 0,073 & 0,062 & 0,072 & 0,059 & 0,067 & 0,054 & 0,058 \\
\hline Dy & 0,029 & & & & & & & & & & & \\
\hline Th & 0,022 & 0,026 & 0,024 & 0,040 & 0,024 & 0,018 & 0,013 & 0,094 & 0,116 & 0,114 & 0,098 & 0,031 \\
\hline $\mathrm{U}$ & 0,009 & 0,000 & 0,007 & 0,007 & 0,010 & & 0,004 & 0,031 & 0,035 & 0,045 & 0,030 & 0,006 \\
\hline $\mathrm{Zr}$ & 1,069 & 1,059 & 1,030 & 1,038 & 1,068 & 1,066 & 1,043 & 1,058 & 1,061 & 1,077 & 0,991 & 1,107 \\
\hline $\mathrm{Hf}$ & & 0,002 & 0,005 & & 0,005 & 0,004 & 0,005 & & & & & \\
\hline $\mathrm{Ti}$ & 1,229 & 1,265 & 1,311 & 1,266 & 1,337 & 1,266 & 1,363 & 1,185 & 1,250 & 1,205 & 1,157 & 1,273 \\
\hline $\mathrm{Fe}$ & 0,387 & 0,415 & 0,425 & 0,410 & 0,382 & 0,386 & 0,398 & 0,385 & 0,248 & 0,246 & 0,213 & 0,347 \\
\hline $\mathrm{Nb}$ & 0,344 & 0,300 & 0,325 & 0,303 & 0,248 & 0,327 & 0,292 & 0,326 & 0,356 & 0,388 & 0,326 & 0,288 \\
\hline $\mathrm{Al}$ & 0,053 & 0,044 & & 0,066 & 0,044 & 0,044 & 0,051 & & & & 0,120 & 0,044 \\
\hline $\mathrm{Si}$ & & 0,063 & 0,082 & 0,106 & 0,056 & 0,062 & 0,037 & & & & 0,210 & 0,050 \\
\hline $\mathrm{Ta}$ & 0,025 & & & & & & 0,013 & & & & & \\
\hline Total & 3,953 & 3,995 & 3,964 & 3,960 & 3,994 & 3,961 & 3,980 & 3,962 & 3,929 & 3,827 & 3,857 & 3,959 \\
\hline
\end{tabular}

A zirconolita encontrada no CAFA ocorre sempre inclusa em feldspato alcalino pertítico ou oligoclásio antipertítico (Figura 2) que são minerais cristalizados precocemente nesses sienitos [23]. Tem-se igualmente inclusos nos feldspatos junto com a zirconolita cristais de baddeleíta, ilmenita, zircão, monazita, thorianita e esfalerita. A inclusão em minerais precoces nesses sienitos indica que a zirconolita é magmática.

Os diagrama ternários ETRs-(Th+U)-(Nb+Ta) e (Th+U)-Ca-(ETRs+Y) (Figura 3) têm sido aplicados para estabelecer a afinidade magmática de cristais de zirconolita. Nesses diagramas percebe-se que os cristais estudados posicionam-se predominantemente no campo das zirconolitas de carbonatitos, com algumas análises ocupando o campo dos sienitos subsaturados em $\mathrm{SiO}_{2}$. Observa-se igualmente na figura 3 a existência de dois conjuntos de cristais de zirconolita, com base nos valores do somatório $(\mathrm{Th}+\mathrm{U})$. A maioria dos cristais estudados apresenta conteúdos de $\mathrm{ThO}_{2}+\mathrm{UO}_{2}$ compreendidos entre $0,8 \%$ e $3,2 \%$ e em uns poucos cristais esses valores variam de $8 \%$ até $10,9 \%$. 


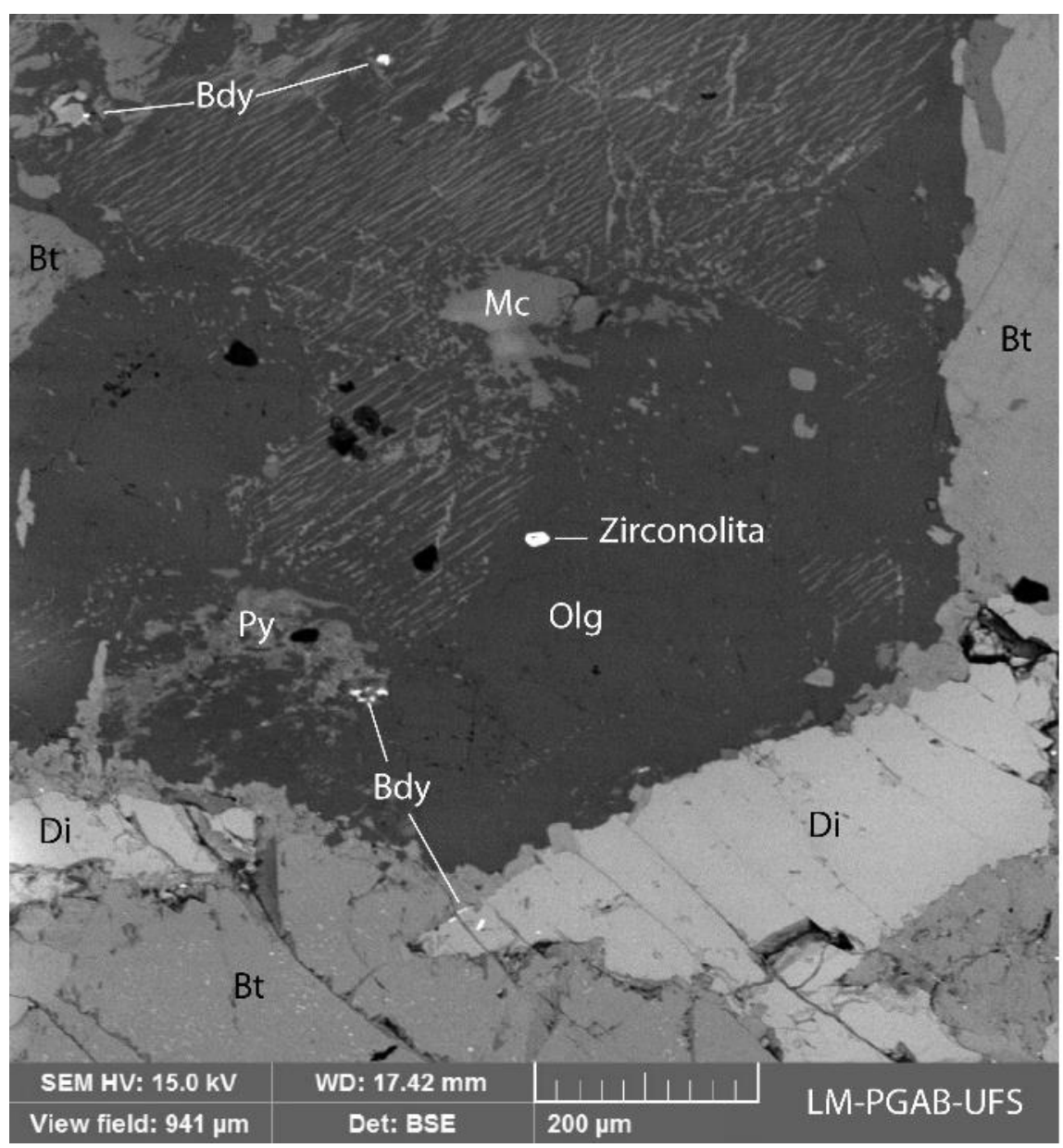

Figura 2: Imagem BSE da textura em sienito (Amostra 2202) apresentando cristal de zirconolita subédrico, com dimensão de $15 \mu \mathrm{m}$ incluso em oligoclásio antipertítico. Biotita (Bt), diopsídio (Di), baddeleíta (Bdy), pirita (Py), microclina (MC), oligoclásio (Olg). As regiões pretas na imagem correspondem a buracos na lâmina polida.

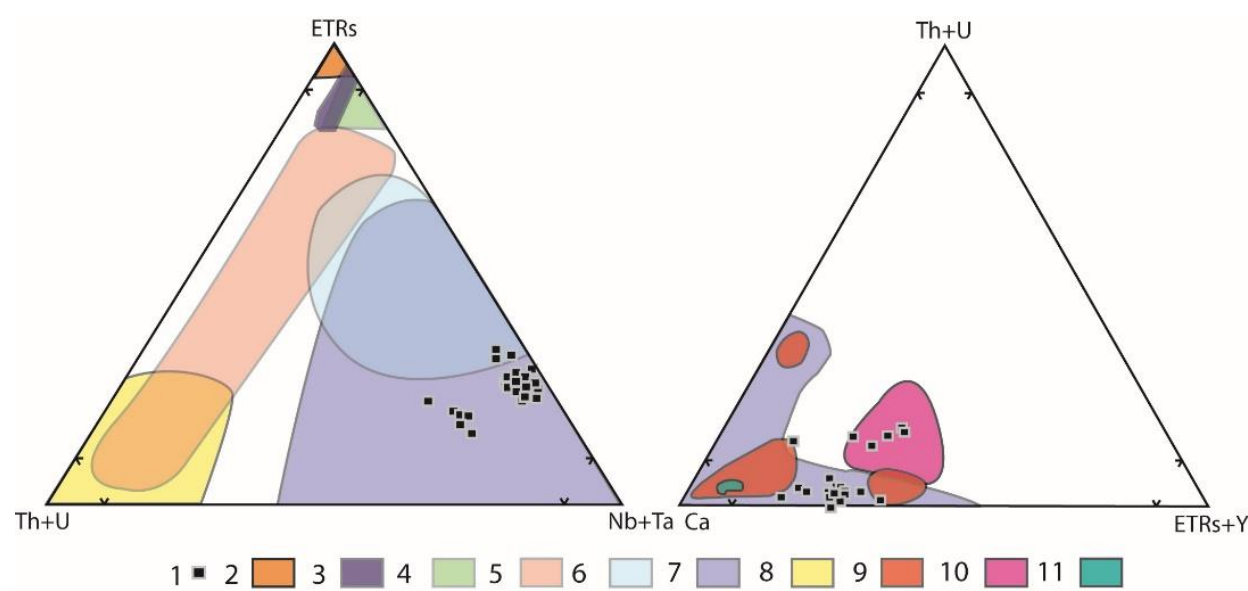

Figura 3. Diagramas catiônicos ETRs-(Th+U)-Nb+Ta [8] e (Th+U)-Ca-(ETRs+Y) [6] com campos delimitando as composições de cristais de zirconolita em diversos tipos de rochas. Análises obtidas nesse trabalho (1), rochas metamórficas (2), rochas lunares (3), rochas ultrabásicas (4), rochas metassomáticas (5), sienitos subsaturados em $\mathrm{SiO}_{2}$ (6), carbonatitos (7), depósito de placers (8), skarns (9), lavas potássicas (10), nódulos mantélicos (11). 
Comparando-se os dados químicos dos cristais de zirconolita do CAFA com aqueles dos carbonatitos de Jacupiranga [8] constata-se que os cristais do CAFA apresentam conteúdos de $\mathrm{ThO}_{2}+\mathrm{UO}_{2}$ superiores aos da zirconolita metamítica de Jacupiranga (CAFA: 10\%; Jacupiranga: 8,4\%). Os conteúdos em $\mathrm{Nb}_{2} \mathrm{O}_{5}+\mathrm{Ta}_{2} \mathrm{O}_{5}$ (CAFA: 10\%; Jacupiranga: 12\%) são similares entre os dois tipos de rocha. Todavia, os conteúdos em ETR $\mathrm{O}_{3}+\mathrm{Y}_{2} \mathrm{O}_{3}$ são bem mais elevados nas amostras estudadas (CAFA: 9\%; Jacupiranga: 2,8\%).

\section{CONCLUSÃo}

Cristais de zirconolita foram identificados pela primeira vez na Província Alcalina do Sul da Bahia em sienitos da intrusão sienítica do Complexo Alcalino Floresta Azul.

A zirconolita ocorre como inclusões em minerais precoces nesses sienitos (feldspato alcalino pertítico e oligoclásio antipertítico), permitindo concluir que a sua cristalização é magmática na Intrusão Sienítica nesse complexo alcalino.

Os dados químicos obtidos por EDS permitiram identificar que as zirconolitas estudadas posicionam-se nos campos de cristais de carbonatitos e de foid-sienitos, existindo dois conjuntos distintos. $\mathrm{O}$ conjunto mais abundante de cristais tem baixos conteúdos de $\mathrm{ThO}_{2}+\mathrm{UO}_{2}$ e outro, menos abundante e com valores mais elevados nesse somatório, foram interpretados como sendo resultado de processo metamítico, comumente presente em cristais de carbonatitos.

\section{AGRADECIMENTOS}

J.J.A. Santos e A.C.S. Pimenta agradecem à Coordenação de Aperfeiçoamento do Pessoal de Nível Superior (CAPES) por suas bolsas de mestrado. Os autores agradecem ao apoio analítico do Laboratório de Microanálise do Condomínio de Laboratórios Multiusuários das Geociências da Universidade Federal de Sergipe. O desenvolvimento desta pesquisa foi possível devido aos recursos obtidos junto ao Conselho Nacional de Desenvolvimento Científico e Tecnológico $(\mathrm{CNPq})$ e à Fundação de Apoio à Pesquisa e à Inovação Tecnológica do Estado de Sergipe (FAPITEC), processos números: 308059/2014-0 (CNPq-PQ), 308754/2013-1 (CNPq-PQ), 473013/2012-4 (CNPq-Universal 2013) e 019.203.02538/2009-7 (PRONEX/FAPITEC/CNPq).

\section{REFERÊNCIAS BIBLIOGRÁFICAS}

1. Ma C, Beckett JR, Comolly Jr HC, Rosman GR. Discovery of Meteoritic Loveringite, Ca (Ti, Fe, $\mathrm{Cr}, \mathrm{Mg})_{21} \mathrm{O}_{38}$, in an Allende Chondrule: Late-Stage Crystallization in a Melt Droplet. $44^{\text {th }}$ Lunar and Planetary Institute Science Conference Abstracts. 2013 March 18-22. The Woodlands, Texas. 44:1443-44.

2. Irving AJ., Kuehner SM, Ziegler K, Conrey RM, Korotev RL, Huber L, Riebe M, Wieler R, Nishiizumi K, Caffee MW, Moser DE, Barker I, Chaoui R. "An Enigmatic Sodic Ferrogabbroic Achondrite from Morocco Containing Zirconolite, Baddeleyite, Fluorapatite and Copper Sulfides." $45^{\text {th }}$ Lunar and Planetary Institute Science Conference Abstracts. 2014 March 17-21. The Woodlands, Texas. 45:2418-19.

3. Wark DA, Reid AF, Lovering JF, El Goresy A. Zirconolite (versus zirkelite) in lunar rocks (abstract). Lunar Science, IV. Sci. Inst. Houston; 1973. 764-6.

4. Platt RG, Wall F, Williams CT, Woolley AR. Zirconolite, chevkinite and other rare earth minerals from nepheline syenites and peralkaline granites and syenites of the Chilwa Alkaline Province, Malawi. Mineral Mag . 1987. 51:253-263, doi: 10.1180/minmag.1987.051.360.07

5. Della Ventura DG, Bellatreccia, F, Williams CT. Zirconolite with significant REE ZrNb(Mn,Fe)O7 from a xenolith of the Laacher See eruptive center, Eifel Volcanic Region, Germany. Can. Mineral. 2000. 38:57-65, doi:10.2113/gscanmin.38.1.57

6. Rajesh VJ, Yokoyama K, Santosh, Arai S, Oh CW, Kim SW. Zirconolite and Baddeleyite in an Ultramafic Suite From Southern India: Eraly Ordovician Carbonatite-Type melts associated with extensional collapse of the Gondwana Crust. The Journal of geology. 2006. 114(2):171-188, doi: $10.1086 / 499571$. 
7. Williams CT, Giere' R. Zirconolite: a review of localities worldwide, and a compilation of its chemical compositions. Bull. Nat. Hist. Mus. Lond. (Geol.). 1996. 52:1-24, doi: 10.3749/canmin.47.5.1087

8. Bellatreccia F, Della Ventura DG, Caprilli E, Williams CT, Parodi GC. Crystal-chemistry of zirconolite and calzirite from Jacupiranga, São Paulo (Brazil). Mineral. Mag. 1999. 63:649-660, doi: $10.1180 / 002646199548817$

9. Harley SL. Mg-Al yttrian zirconolite in a partially melted sapphirine granulite, Vestfold Hills, East Antarctica. Mineralogical Magazine. 1994. 58:259-269, doi: 10.1180/minmag.1994.058.391.08

10. Gieré R. Zirconolite, allanite and hoegbomite in a marble skarn from the Bergell contact aureole: implications for mobility of $\mathrm{Ti}, \mathrm{Zr}$ and REE. Contrib. Mineral. Petrol. 1986. 93:459-470, doi:10.1007/BF00371716

11. Haifler J, Škoda R. Chemical characterisation and XRD study of zirconolite from Håkestad alkaline pegmatite, Larvik Plutonic Complex, south Norway. Acta Mineralogica-Petrographica. $5^{\text {th }}$ Mineral Sciences in the Carpathians Conference and $3^{\text {rd }}$ Central-European Mineralogical Conference, Abstract Series. 2012 20-21 April. Szeged. 7:51.

12. Purtscheller, F, Tessadri R. Zirconolite and baddeleyite from metacarbonates of the Oetztal-Stubai complex (northern Tyrol, Austria). Mineralogical Magazine. 1985. 49(353):523-529, doi: 10.1180/minmag.1985.049.353.05

13. Nishio D, Minakawa T. Baddelcyite, zirconolite and calzirtite in lateritic rocks from Ryoke and Chichibu Terranes, Japan. Journal of Mineralogical and Petrological Sciences. 2004. 99(1):42-53, doi:10.2465/jmps. 99.42

14. Gieré R, Lumpkin GR, Williams CT. Chemical characteristics of natural zirconolite. Schweiz. Mineral. Petrogr. Mitt. 1998. 78:433-459.

15. Stucki A, Trommsdorff, V, Gunthe D. Zirconolite in metarodingites of Penninic Mesozoic ophiolites, Central Alps. Schweiz. Mineral. Petrogr. Mitt. 2001. 81:257-265.

16. Santos JJA, Rosa MLS, Conceição H. Primeira Ocorrência de Ancilita no Estado da Bahia: Mineral Acessório em Foid Sienitos do Complexo Alcalino Floresta Azul. Scientia Plena. 2014. 10(10):1-6.

17. Pimenta ACS, Conceição H, Rosa MLS. Mineralogia das Vênulas Brancas e do Material Afanítico Preto em Planos de Fraturas em Sodalititos de Cor Azul do Stock Itajú do Colônia, Bahia. Scientia Plena. 2014. 10(5):1-9.

18. Rosa MLS, Conceição H., Menezes RCL, Macambira MJB, Galarza MA, Cunha MP, Menezes RCL, Marinho MM, Cruz Filho BE, Rios DC. Neoproterozóic anarogenic magmatism in the southern Bahia alkaline Province of NE Brazil. Journal Lithos. 2007. 97:88-97.

19. Almeida RN. Caracterização Litogeoquímica das Rochas Subvulcânicas da Região de Potiraguá, Sul do Estado da Bahia [dissertação]. Salvador: Universidade Federal da Bahia; 2006. 65 p.

20. Oliveira RCLM. Idade Petrografia e Geoquímica do Magmatismo Anorogênico Criogeniano e Toniano no Sul do Estado da Bahia [Tese]. Salvador: Universidade Federal da Bahia; 2010. 96 p.

21. Salinas ACM. Geoquímica da Intrusão Granítica do Complexo Alcalino Floresta Azul, Província Alcalina do Sul do Estado da Bahia [Dissertação]. Salvador: Universidade Federal da Bahia; 2011. $85 \mathrm{p}$.

22. Menezes RCL, Conceição H, Rosa MLS, Macambira MJB, Galarza MA, Rios DC. Geoquímica e geocronologia de granitos anorogênicos tonianos (ca. 914-899 ma) da Faixa Araçuaí no sul do Estado da Bahia. Revista Geonomos. 2012. 20(1):1-13.

23. Santos JJA. Petrografia da Intrusão Sienítica do Complexo Alcalino Floresta Azul, Sul do Estado da Bahia (Graduação). São Cristóvão: Universidade Federal de Sergipe; 2013.79 p.

24. Rosa MLS, Conceição H, Macambira MJB, Marinho MM, Marques LS. Idade ( $\mathrm{Pb}-\mathrm{Pb})$ e aspectos petrográficos e litogeoquímicos do Complexo Floresta Azul, Sul do Estado da Bahia. Revista Brasileira de Geociências. 2003. 33:13-20.

25. Bayliss P, Mazzi F, Munno R, White TJ. Mineral nomenclature: zirconolite. Mineral. Mag. 1989. 53:565-569, doi: 10.1180/minmag.1989.053.373.07

26. Gatehouse BM, Grey IE, Roderick JH, Rossel HJ. Zirconolite, $\mathrm{CaZr}_{\mathrm{x}} \mathrm{Ti}_{3-\mathrm{X}} \mathrm{O}_{7}$ : Structure Refinements for Near-End-Member Compositions with $\mathrm{x}=0.85$ and 1.30. Acta Crystal B. 1981. 37:306-312, doi: $10.1107 /$ S0567740881002914

27. Mazzi F, Munno R. Calciobetafite (new mineral of the pyrochlore group) and related minerals from Campi Flegrei, Italy: crystal structures of polymignyte and zirkelite: comparison with pyrochlore and zirconolite. Am. Mineral. 1983. 68:262-276,

28. Kesson SE, Sinclair WJ, Ringwood AE. Solid solution limits in SYNROC zirconolite. Nucl. Chem. Waste Manag. 1983. 4:259-65, doi:10.1016/0191-815X(83)90019-0

29. Heaman LM, LeCheminant AN. Paragenesis and U-Pb systematicsof baddeleyite $\left(\mathrm{ZrO}_{2}\right)$. Chemical 
Geol. 1993. 110:95-126, doi:10.1016/0009-2541(93)90249-I

30. Gieré, R. Hydrothermalmobility of $\mathrm{Ti}, \mathrm{Zr}$ and REE: examples from the Bergell and Adamello contact aureoles (Italy). Terra Nova. 1990. 2:60-67, doi:10.1111/j.1365-3121.1990.tb00037.x

31. Gieré, R., Williams, C.T. REE-bearing minerals in a Ti-rich vein from the Adamello contact aureole (Italy). Contrib. Mineral. Petrol. 1992. 112:83-100, doi:10.1007/BF00310957

32. Ried F. Titanmobilität: Metasomatische, titanreiche Adern am Kontakt von Dolomitmarmoren zur Bergeller Intrusion. [PhD. Thesis]. ETH Zürich; 1994. 204 p. 